\title{
Data-poor stock assessment of fish stocks co-exploited by commercial and recreational fisheries: Applications to pike Esox lucius in the western Baltic Sea
}

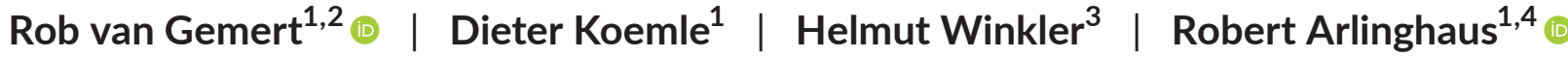

\author{
${ }^{1}$ Department of Biology and Ecology of \\ Fishes, Leibniz Institute of Freshwater \\ Ecology and Inland Fisheries, Berlin, \\ Germany \\ ${ }^{2}$ Department of Aquatic Resources, \\ Institute of Freshwater Research, Swedish \\ University of Agricultural Sciences, \\ Drottningholm, Sweden \\ ${ }^{3}$ Institute of Biodiversity and Zoology, \\ University of Rostock, Rostock, Germany \\ ${ }^{4}$ Division of Integrative Fisheries \\ Management, Faculty of Life Sciences, \\ Humboldt-Universität zu Berlin, Berlin, \\ Germany \\ Correspondence \\ Rob van Gemert, Department of Biology \\ and Ecology of Fishes, Leibniz Institute of \\ Freshwater Ecology and Inland Fisheries, \\ Müggelseedamm 310, Berlin 12587, \\ Germany. \\ Email: rob.van.gemert@slu.se \\ Funding information \\ European Maritime Fisheries Fund (EMFF) \\ of the EU and the State of Mecklenburg- \\ Vorpommern (Germany), Grant/Award \\ Number: B 730117000069 and MV-I.18- \\ LM-004
}

\begin{abstract}
Information on catch and effort of recreational angling in mixed-use fisheries (coexploited by commercial and recreational fishers) is often scarce, preventing the application of data-rich stock assessments typically performed for industrialised commercial fisheries. This study shows how data-poor stock assessment methods developed for marine fisheries, particularly a model class labelled as "catch-only" models (COMs), offer a possible solution. As a case study, COMs are used to assess a northern pike Esox lucius L. stock around the German Baltic island of Rügen. Multiple COMs were fitted to a time series of total pike removals, and their outputs were used as explanatory variables in ensemble models. The stock was found to be fully exploited and currently declining. This study highlights the potential for using COMs to determine status of previously unassessed coastal and freshwater stocks facing recreational fishing pressure and demonstrates how incorporating recreational removals is crucial for achieving reliable insights into the status of mixed-use stocks.
\end{abstract}

\section{KEYWORDS}

catch-only models, coastal stocks, ensemble models, freshwater stocks, mixed-use fisheries, stock status

\section{1 | INTRODUCTION}

The management of mixed-use fisheries, that is fisheries that are co-exploited by commercial and recreational fishers, poses many challenges. For instance, commercial and recreational fisheries often have different management objectives (Ahrens et al., 2020; Arlinghaus et al., 2019), and the differences in goals and behaviours increase with the diversity of stakeholders (Mardle et al., 2004; Pascoe et al., 2009). The sustainable management of mixed-use fisheries requires monitoring and managing both its commercial and recreational components, because the combined action of both sectors is responsible for the total fishing mortality induced on a stock (Berkes, 1985; Cooke \& Cowx, 2004; Post et al., 2002).

A common precondition for sustainability in fisheries is the existence of regular stock assessments (Melnychuk et al., 2017). Stock assessments employ a variety of methods depending on the data available. The most reliable data-rich methods, such as virtual population analysis and statistical catch-at-age models, require data on catch, effort, and the age/length/weight composition, preferably from both the fishery users as well as from independent scientific

This is an open access article under the terms of the Creative Commons Attribution-NonCommercial-NoDerivs License, which permits use and distribution in any medium, provided the original work is properly cited, the use is non-commercial and no modifications or adaptations are made.

(c) 2021 The Authors. Fisheries Management and Ecology published by John Wiley \& Sons Ltd. 
surveys (Hart \& Reynolds, 2002; Hilborn \& Walters, 1992). The management of industrial commercial fisheries appears to become increasingly effective due to the presence of frequent and high-quality stock assessments, with many assessed stocks showing rebuilding from previously overfished states (Hilborn et al., 2020). However, the collection of data required for such assessments is costly (Mangin et al., 2018), and therefore, high-quality data to pursue stock assessments are rarely available for many small-scale commercial (Andrew et al., 2007; Graaf et al., 2015; Prince \& Hordyk, 2019) and recreational fisheries (Arlinghaus et al., 2019; Post et al., 2002). As a result, mixed-use fisheries often face a severe lack of data, preventing the application of stock assessment practices common to industrial commercial fisheries.

When there is insufficient data available for performing a traditional data-rich stock assessment, the fishery is usually referred to as data-poor or data-limited (Prince \& Hordyk, 2019). Many small-scale commercial and recreational fisheries are characterised as such, with aggregated catch or landings data often being the only form of data available (Newman et al., 2015; Vasconcellos \& Cochrane, 2005). One alternative to traditional stock assessment is to infer stock status from trends in catch data, as is done in stock status plots (Froese \& Kesner-Reyes, 2002; Grainger \& Garcia, 1996; Pauly, 2007). However, because catches do not necessarily track changes in underlying biomass, such catch-based methods can result in incorrect conclusions (Branch et al., 2011; Carruthers et al., 2012; Daan et al., 2011). To overcome this problem and still be able to make predictions on stock status using aggregated catch/landings data, increasingly sophisticated models have been developed that either rely on population dynamics models (Martell \& Froese, 2013; Vasconcellos \& Cochrane, 2005) or statistical correlations with datarich assessed stocks (Costello et al., 2012; Zhou et al., 2017). These data-poor models are referred to as catch-only models (COMs) (Free et al., 2020). COMs designed to estimate stock status time series can be divided into two broad categories: mechanistic and empirical COMs (Free et al., 2020).

Mechanistic COMs fit a population dynamics model to the catch data and make assumptions regarding parameter values to make up for the lack of other data. Mechanistic COMs include models such as "catch maximum sustainable yield" (Catch-MSY) (Martell \& Froese, 2013) and "state-space catch-only model" (SSCOM) (Thorson et al., 2013). Empirical COMs use information from data-rich assessed stocks to find statistical associations between catch, stock status and other covariates. Empirical COMs include models such as "modified panel regression model" (mPRM) (Rosenberg et al., 2014) and "Zhou boosted regression tree" (zBRT) (Zhou et al., 2017). COMs are not as accurate in predicting stock status as data-rich statistical catch-at-age models, but they offer a temporary stepping stone when the absence of some data currently prevents a full data-rich assessment (Free et al., 2020). In particular, statistical models that ensemble the estimates of individual COMs provide the best assessment of stock status based on catch data alone (Anderson et al., 2017; Free et al., 2020).
In addition to using quantitative models to determine the status of data-poor stocks, assessments based on traditional ecological knowledge of local residents or local resource users have also been performed (Berkes et al., 2000). Although individual perceptions may conflict with scientific findings (Daw et al., 2011; O'Donnell et al., 2010), such local knowledge may be one of the few sources of information on the development history of many fisheries (Johannes, 1998). Furthermore, studies that have compared traditional ecological knowledge with independent stock assessments have often found that model outcomes align with local understanding (Aswani \& Hamilton, 2004; Neis et al., 1999) and that local users can approximate scientific understanding of ecological relationships in fish stocks (Aminpour et al., 2020). Thus, the knowledge of local residents can be used to evaluate whether scientific and stakeholder perspectives agree.

This study aims to demonstrate how COMs can be used in an ensemble approach to assess the status of data-poor mixed-use fish stocks. For this, a northern pike Esox lucius L. (henceforth "pike") fishery in the coastal lagoons around the island of Rügen in the western Baltic Sea, Germany, is used as a case study. This coastal pike stock is targeted by both recreational and commercial fishers (Arlinghaus et al., 2021), but regular stock assessments are lacking, and disparate perspectives about stock status have emerged among stakeholders that contribute to local conflict (Vogt, 2020). To help solve these issues, the status of the coastal pike stock in the lagoons around Rügen is assessed using seven different COMs, and a state-of-theart ensemble model approach is used (Anderson et al., 2017) to account for individual model biases. Furthermore, local stakeholder perceptions on the development of the stock are collected to compare stakeholder perspectives with the assessment results. Thus, using a practically relevant example of an ongoing management dilemma in a mixed-use coastal fishery, this study demonstrates how COMs can be used as an initial method for the assessment of datapoor mixed-use stocks, being aware that it is not a perfect substitute for more data-rich approaches.

\section{2 | MATERIALS \& METHODS}

\subsection{Study area}

The study focussed on the pike stock around the German island of Rügen, which is located in the western Baltic Sea (Figure 1). There are multiple lagoon-type brackish water bodies located around this island, which are connected to the Baltic Sea (Schubert \& Telesh, 2017). These lake-like water bodies vary in salinity from nearly fresh to nearly that of the neighbouring Baltic (Placke et al., 2018) and exhibit salinities below 14 psu year-round, that is oligo to mesohaline brackish conditions (Schiewer, 2008; Schumann et al., 2006). Although pike is a freshwater fish, the species is able to tolerate the brackish water present in the lagoon waters and is known to spawn and recruit successfully in the brackish conditions around Rügen (Möller et al., 2019). 

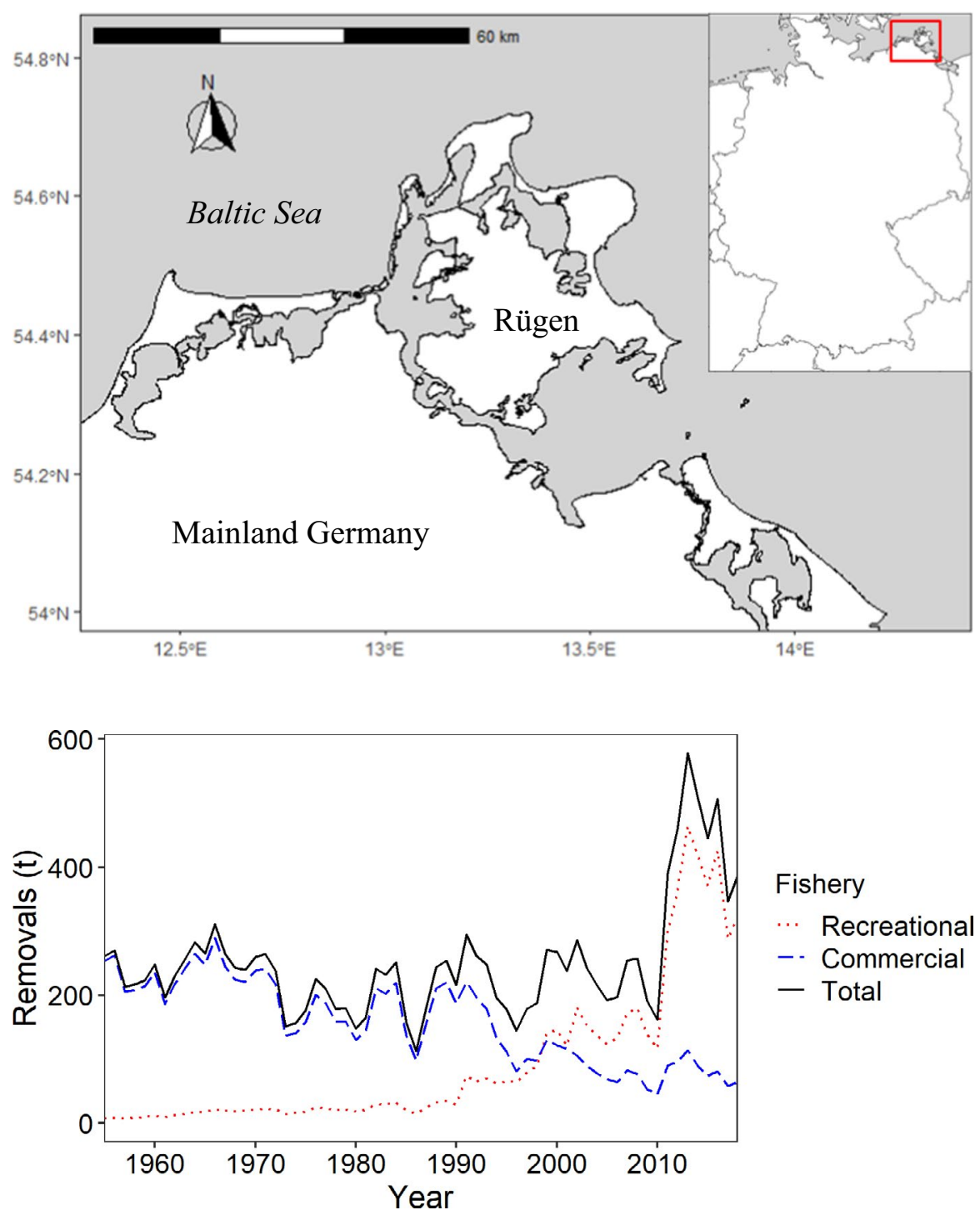

The pike stock inhabiting the lagoons of Rügen has been exploited by small-scale coastal commercial fishers mostly using passive gear since at least the late $19^{\text {th }}$ Century (Winkler, 1989; Winkler $\&$ Debus, 2006) and most probably long before that. For much of the $20^{\text {th }}$ Century, the pike stock was a target for commercial fishers, helped by the guaranteed price-per-unit-weight that was maintained by the East Germany (GDR) Government (Döring et al., 2020). However, after Germany's reunification, pike became a bycatch species for most coastal commercial fishing enterprises and is today the primary target for only a small number of dedicated commercial pike fishers. However, the species continues to be captured in gillnets, fyke nets and with long-lines up to the present day.

Recreational angling, which was also practised in the Rügen lagoons during GDR times, has been increasing in popularity since the German reunification (Figure A5, Appendix S1), with pike being particularly popular (Arlinghaus et al., 2021). Likely owing to the large size of pike in the Rügen lagoons, the area is attractive for tourist and resident anglers alike (Arlinghaus et al., 2021; Weltersbach et al., 2021), with pike larger than one metre being frequently caught (Arlinghaus et al., 2021).

\section{Fishery \\ ‥ Recreational \\ - Commercial \\ - Total}

FIGURE 1 A map of the German Baltic island of Rügen and its location within Germany
FIGURE 2 Total estimated removals by both commercial and recreational fishers in the Rügen area over time (solid black). Shown too are removals by commercial fisheries over time (dashed blue) and reconstructed removals by recreational fishers over time (dotted red)

\subsection{Catch time series data}

A time series of annual commercial pike landings from 1976-2018 from the lagoons around Rügen was obtained from the State Office for Agriculture, Food Safety and Fisheries (LALLF) of the German state Mecklenburg-Vorpommern (M-V). In addition, commercial removals from 1969-1975 and from 1955-1968 were extracted from Winkler (1991) and from records generated from annual official fisheries reports published by the Institut für Hochseefischerei und Fischverarbeitung Rostock of the former GDR, respectively (Figure 2).

A time series of recreational removals was not available for the Rügen pike stock, as recreational removals are not actively monitored in the area. However, given the popular recreational fishery for Rügen pike, it was considered important to include recreational removals in the time series of total removals. Recreational removals were reconstructed according to the guidelines provided by Zeller et al. (2006). Data from two telephone-diary studies performed among recreational fishers in the region (Dorow \& Arlinghaus, 2011; Lucas, 2018; Weltersbach et al., 2021) were used as anchor points. These studies estimated total pike removals in the Rügen area from 
a random sample of participating recreational fishers, found via telephone screening surveys using random digit dialling, for the years 2006/2007 and 2014/2015. From these anchor points, and using additional quantitative data such as proxies for angling effort, recreational removals were interpolated and extrapolated for the rest of the time series (Figure 2).

The reconstruction of recreational removals of the Rügen pike (detailed in Appendix S1) can be summarised as follows. For the year 2007, data were available on resident angler harvest and catch-andrelease rate, and the number of angling trips taken in the Rügen area by resident anglers (Dorow \& Arlinghaus, 2011). Comparable data were available for 2015 , not only for resident but also for tourist anglers (Lucas, 2018; Weltersbach et al., 2021). These anchor points were supplemented with time series data on the annual number of resident fishing licenses issued in $M-V$ as given by LALLF, the annual number of coastal recreational angling licenses issued in $M-V$ as given by LALLF, and the membership numbers of the East German angling association (DAV) prior to the German reunification (VDFF, 1998). The 2007 and 2015 data on resident angling trips were then used together with the time series on coastal recreational angling licenses to estimate a 1991-2018 time series on resident angling trips, assuming a linear increase in trips per license for resident anglers between 2007 and 2015. Similarly, the 2015 data on tourist angler trips were used together with the time series on coastal recreational angling licenses to estimate a 1991-2018 time series on tourist angling trips, assuming a constant number of trips per license for tourist anglers based on the 2015 data. Then, DAV membership data were used to extrapolate this recreational effort time series back to 1955 .

Available time series data on commercial Rügen pike removals and the annual number of commercial fishing vessels registered in the area, as given by the European Fleet Register, were used to estimate a commercial catch-per-unit-effort (CPUE) time series (landings per boat); this assumed a constant commercial effort in the years for which there was a lack of data (1955-1991). This commercial CPUE time series was used together with the 2007 and 2015 data on recreational fisher catch rates to estimate a 1991-2018 time series of recreational catches, assuming constant proportionality between recreational and commercial CPUE for all years. Resident and tourist removals were subsequently estimated by accounting for the release rates of 2007 and 2015, assuming a linear decrease in resident release rate between 2007 and 2015 and assuming that tourist release rate remained constant to its 2015 value, and furthermore assuming a release mortality for pike of $7.8 \%$ (Hühn \& Arlinghaus, 2011). Lastly, the reconstructed recreational removals of 1991 were used to extrapolate recreational removals back to 1955 , by assuming a constant proportionality between recreational and commercial CPUE.

\section{3 | Models}

First, a suite of individual COMs were used to estimate current status of the Rügen pike stock. The results of these models were then inserted into several different "trained" statistical models, following the ensemble model approach as described by Anderson et al. (2017), providing an estimate of current stock status. Lastly, the outcome of the ensemble analysis was used to assign weights to COM time series estimates of biomass and fishing mortality, providing an estimate of past stock status. The analysis was performed in $\mathrm{R}$ version 3.6.1 (R Core Team, 2019), using the "datalimited" (Anderson et al., 2016) and "datalimited2" (Free, 2018) packages for the COMs, and the "randomForest" (Liaw \& Wiener, 2002) and "gbm" (Greenwell et al., 2019) packages for the ensemble models.

Using COMs that had their performance tested by Free et al. (2020), seven individual COMs were fitted to the reconstructed removal data of the Rügen pike stock. This included five COMs that fit a population dynamics model, and two COMs that find statistical associations using data-rich assessed stocks. Each of the COMs returned an estimate of $B / B_{M S Y}$ (population biomass relative to population biomass that produces maximum sustainable yield) over the course of the catch time series, including a 95\% confidence interval. Furthermore, parameters and reference points returned by some, but not all, COMs include fishing mortality $F$ (from the pooled population), fishing mortality that gives $M S Y F_{M S Y}, B, B_{M S Y}$, MSY, intrinsic population growth rate $r$ and population carrying capacity $k$. The COMs that were used were Catch-MSY (Martell \& Froese, 2013), "catch maximum sustainable yield 2" (CMSY) (Froese et al., 2017), "catch-only model with sampling-importance-resampling" (COMSIR) (Vasconcellos \& Cochrane, 2005), SSCOM (Thorson et al., 2013), mPRM (Rosenberg et al., 2014), "optimised catch-only model" (OCOM) (Zhou et al., 2018), and zBRT (Zhou et al., 2017). A brief explanation of each model is provided in Appendix S2.

An ensemble model approach (Anderson et al., 2017) was used in an attempt to resolve the potential discrepancies in the different COMs that were fitted to the data, which yielded different results due to inherent biases resulting from the different methods and assumptions used (Free et al., 2020). Firstly, for each COM, the estimated values for mean and slope of $B / B_{M S Y}$ were taken, and $a$ mean for the last 5 years of data was calculated. Secondly, these COM means were inserted as covariates into three different statistical models (i.e. ensemble models) that were trained on stocks with known status, thereby obtaining an ensemble estimate of the mean and slope of $B / B_{M S Y}$ for the last 5 years. The three statistical models that were used for this were a linear model, a random forest and a boosted regression tree.

To train the three ensemble models with known data, simulated exploitation time series were used for 5760 different hypothetical stocks. For this, the exploitation time series simulated by Rosenberg et al. (2014) were used, obtained via the "fishensembles" R package (Anderson, 2021). These time series varied in both life-history parameters and fishing regime, contained both process and observation error, and contained ten different time series iterations for each stock. Then, for each hypothetical stock, each of the seven COMs was fitted to its simulated catch time series, giving seven estimates of a time series for $B / B_{M S Y}$ for each stock iteration. Next, for each of these time series, the mean and slope of $B / B_{M S Y}$ were 
taken and used to calculate a mean over the last 5 years of data. Lastly, the statistical ensemble models were trained. For this, the simulated stock time series was divided into a training and a testing dataset. The training dataset was composed of the first nine out of ten iterations of each of the 5760 hypothetical stocks time series and used to train the ensemble models. Either the mean or the slope of recent $B / B_{M S Y}$ estimated by the seven COMs for the simulated stock time series were used as seven independent variables, and the associated true mean or slope of recent $B / B_{M S Y}$ of all simulated stocks were used as the dependent variable. To prevent over-fitting of the random forest and boosted regression tree models, the "caret" package was used (Kuhn, 2020) in R to identify the optimal parameter combination for both the $B / B_{M S Y}$ mean and slope model fits. Using a 10-fold cross-validation repeated ten times, optimal parameter combinations were identified as those that resulted in the smallest root-mean-square deviation. Following the results of this tuning procedure (Appendix S3), Random forest models were fitted for both mean $B / B_{M S Y}$ and its slope using three randomly selected predictors and 1000 trees, the boosted regression tree model was fitted for mean $B / B_{M S Y}$ using 9500 trees, an interaction depth of 10 , and a shrinkage of 0.005 , and the boosted regression tree was fitted for $B / B_{M S Y}$ slope using 7000 trees, an interaction depth of 10 , and a shrinkage of 0.005 , keeping all other parameters to their default setting. Performance of both the COMs and ensemble models was analysed in Appendix S4.

After the ensemble models had been trained with known data, they were used to estimate the status of the Rügen pike stock. For this, the outcomes of the seven COMs (estimates of the mean value and mean slope of $B / B_{M S Y}$ of the Rügen pike stock over the last 5 years of data) were used as the independent variables, whilst retaining the values of the regression coefficients estimated in the training of the ensemble models. In this way, each ensemble model provided an estimate of the mean and slope of $B / B_{M S Y}$ for the Rügen pike over the last 5 years of data. To study the importance of incorporating recreational removals into the total removals time series, this process was repeated using only the commercial landings of pike as input to the COMs and the subsequent ensembles.

\subsection{Estimating $F$ and $F_{M S Y}$}

Aside from a $B / B_{M S Y}$ time series, four mechanistic COMs (CatchMSY, CMSY, COM-SIR and OCOM) also estimate $F$ and $F_{M S Y}$. These COMs' weighted means of $B, B_{M S Y}, F$ and $F_{M S Y}$ were used to construct a Kobe plot, showing the recent trend in stock status relative to $F_{M S Y}$ and $B_{M S Y}$. To construct a weighted mean of each of these variables, COM-specific weights were assigned; these weights being based on each COM's percentage error of its estimate of mean $B / B_{M S Y}$ over the last 5 years, compared with the mean of the ensemble estimates. Percentage error $p_{\text {error }}$ of COM $i$ was calculated as:

$$
p_{\text {error }, i}=\frac{S_{i}-S_{\mu}}{S_{\mu}}
$$

where $S$ is the COM estimate of mean $B / B_{M S Y}$ over the last 5 years, and $S_{\mu}$ is the mean of the ensemble estimates of mean $B / B_{M S Y}$ over the last 5 years. Next, weight $w$ of COM $i$ was calculated as the reciprocal of the absolute value of $p_{\text {error }}$ :

$$
w_{i}=\frac{1}{\left|p_{\text {error, } i}\right|}
$$

Thus, if a COM estimate of $B / B_{M S Y}$ had a larger deviance from the ensemble model mean, then it received a smaller weight. Weights were subsequently normalised according to:

$$
w_{\text {norm }, i}=\frac{w_{i}}{\sum w_{i}}
$$

The normalised weight $w_{\text {norm }}$ of a COM was then used to calculate weighted means of $B, B_{M S Y}, F$ and $F_{M S Y}$ for each of the COMs that estimated these values. Performance of this weighting procedure was estimated in Appendix S4, using the testing dataset of the simulated stocks.

Sensitivity tests were performed to analyse the sensitivity of the models to alternative parameter values and to test a number of the assumptions made in the reconstruction of recreational removals. The methodology and results of these tests are described in detail in Appendix S5. In summary, first an elasticity analysis was performed to test the sensitivity of the model results to changes in COM parameter values. Each parameter was varied by $50 \%$, and a model was considered sensitive to a given parameter when the model result deviance from its base run estimate was greater than $50 \%$. Second, the sensitivity of the model results to assumptions made during the reconstruction of the recreational removals was examined. The recreational removals time series was reconstructed through various alternative methods, the COMs and ensemble models were run with the resulting time series of total removals, and the deviance of each model's result from its base run was examined.

\subsection{Stakeholder perceptions of stock trends}

To gain insight in how different stakeholders perceived the development of the Rügen pike stock, a short questionnaire was constructed and distributed among key stakeholder groups (anglers, angling guides, commercial fishers, non-governmental organisations and fisheries agency staff). Among other things, respondents were asked how they perceived the stock of pike to have changed within the time-frame between today and the first time they fished at the Rügen lagoons. The same question was asked regarding the stock development of pike greater than one metre in length. Responses were measured on a five-point Likert scale from "strong decrease" to "strong increase."

The survey was administered through a snowball technique to both resident and tourist anglers as well as angling guides, fishers and other stakeholders. Data were further collected on an angling 
exhibition in Rostock in June 2019 and through local angling guides. The total sample size numbered 258 observations. The resulting data were not representative for the population-level perceptions, but allowed for the gathering of initial insights for the most heavily engaged stakeholders, and to compare stock trends derived from the COMs with stakeholder perspectives.

\section{$3 \mid$ RESULTS}

The seven COMs predicted different historic patterns in the $B / B_{M S Y}$ trend of the pike stock in the Rügen area (Figure 3). Notably, zBRT predicted a severely depleted stock status in the 1970s and 1980s, whilst most other COMs predicted a status of $B / B_{M S Y}$ remaining around or above 1 for the majority of the time series. The mPRM, SSCOM and ZBRT models estimated a highly variable trajectory of $B / B_{M S Y}$ over time, whereas Catch-MSY, CMSY, COM-SIR and OCOM estimated a smoother trajectory. Estimates of current $B / B_{M S Y}$ varied as well, with two COMs estimating a current $B / B_{M S Y}$ greater than 1 , one COM estimating it lower than 1 , and four COMs estimating it to be around 1. However, almost all COMs consistently estimated a decline in $B / B_{M S Y}$ in recent years, with the exception of COM-SIR.
The different ensemble models predicted similar values for mean $B / B_{M S Y}$ in the past 5 years and all predicted a negative slope of recent $B / B_{M S Y}$ (Table 1). Although all ensemble models predicted a 5 -year mean of recent $B / B_{M S Y}$ above 1 , extrapolating this mean with each ensemble's estimated slope $B / B_{M S Y}$ suggested that current $B / B_{M S Y}$ of the Rügen pike stock is around or even slightly below 1 (Figure $4 a$ ). Thus, based on the ensemble model results, the Rügen pike stock is fully exploited, but may also be slightly growth overfished when judged by MSY.

The performance analysis in Appendix S4 showed that the ensemble models can be expected to perform better than the individual COMs, giving a more accurate and unbiased estimate of recent $B / B_{M S Y}$

When recreational removal data were left out of the analysis, and the models were provided with only the commercial catch data, differences from the original estimates of the catch-only and ensemble models could be observed (Figure 4b). When not considering recreational fishers, the pike stock appeared in a much poorer and highly overfished state than when recreational removals were included.

The Catch-MSY model was assigned the greatest weight (Table 2). The resulting weighted means of $B, B / B_{M S Y}, F$ and $F / F_{M S Y}$
FIGURE $3 \quad \mathbf{B} / \mathbf{B}_{\text {MSY }}$ trends as estimated by seven individual catch-only models: catch maximum sustainable yield (a), catch maximum sustainable yield 2 (b), catchonly model with sampling-importanceresampling (c), modified panel regression (d), optimised catch-only model (e), state-space catch-only model (f) and Zhou boosted regression tree (g). Shaded areas indicate $95 \%$ confidence intervals. The dotted line indicates $B / B_{M S Y}$, with $B / B_{M S Y}$ values lower than 1 indicating overfishing, and higher than 1 indicating no overfishing

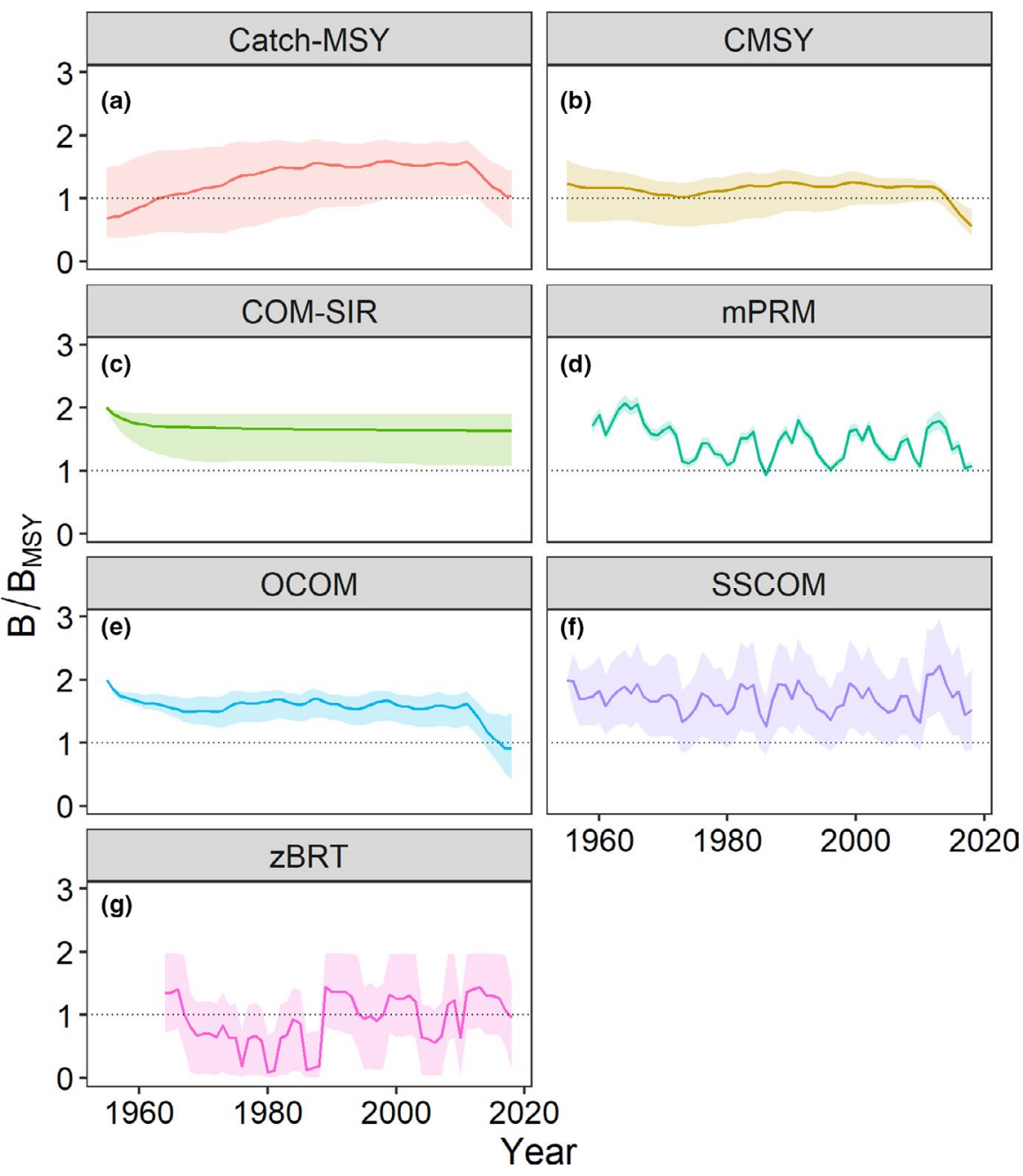


TABLE 1 For the last five years of data, COM and ensemble model estimates of the mean value of $B / B_{M S Y}$ and the mean slope of $B / B_{M S Y}$

\begin{tabular}{lll} 
Model & Mean & Slope \\
COM & 1.1 & \\
Catch-MSY & 0.78 & -0.062 \\
CMSY & 1.6 & -0.12 \\
COM-SIR & 1.3 & -0.00062 \\
mPRM & 1.0 & -0.15 \\
OCOM & 1.7 & -0.076 \\
SSCOM & 1.2 & -0.11 \\
zBRT & 1.2 & -0.10 \\
COM mean & & -0.088 \\
Ensemble & 1.3 & \\
Boosted regression & 1.2 & -0.13 \\
Linear model & 1.2 & -0.12 \\
Random forest & 1.2 & -0.15 \\
Ensemble mean & & -0.13 \\
\hline
\end{tabular}

Note: Shown in bold are the mean values of all COMs and all ensemble models, respectively.

were visualised as a Kobe plot (Figure 5) and indicated that the stock had a healthy status and was not experiencing growth overfishing ( $F>F_{\text {MSY }}$ ) up until 2012, after which overfishing gradually reduced stock biomass to around $B_{\mathrm{MSY}}$. Thus, the weighted means suggest that the pike stock is currently experiencing growth overfishing and are fully exploited. This result does not differ greatly from the results of the ensemble models, which predicted a current $B$ state slightly below $B_{M S Y}$. Using the model weights, estimates of current state of the Rügen pike stock, fisheries reference points and population growth parameters were calculated from their individual COM estimates (Table 3). The performance analysis of the weighting procedure (Appendix S4) suggests that absolute biomass estimates are generally underestimated, but that the relative status estimate (e.g. $\left.B / B_{M S Y}\right)$ can be expected to be without directional bias, although large outliers are possible.

The various sensitivity analyses showed that the mean of the ensemble model estimates was generally robust to parameter settings and model assumptions (Appendix S5). The elasticity test showed that, in general, the models were insensitive to changes in parameter values, with the greatest sensitivity being to changes in the prior for final year biomass range. Next, regarding the assumption of constant commercial effort before 1991, the results remained largely unchanged when different assumptions were made regarding the trend of commercial effort before 1991. Lastly, reconstructing recreational removals in a variety of different ways changed the mean of ensemble estimates of mean $B / B_{M S Y}$ over the last 5 years to only a limited degree, with a positive deviance of $20.8 \%$ being the highest among all different reconstructions, followed by a positive deviance of $14.2 \%$

From the stakeholder survey, when asked about their perceptions of the development of the Rügen pike stock, respondents mostly indicated a perceived decline over time in large pike of the Rügen stock as well as a perceived decline for the Rügen pike stock in general (Figure 6). This perceived decline was greatest among guides and those anglers who were out with a guide when interviewed. Thus, stakeholders agreed with the model results in estimating a recent decline of the pike stock.

\section{4 | DISCUSSION}

Mixed commercial-recreational fisheries can be challenging to manage because commercial and recreational fisheries typically have divergent management objectives (Ahrens et al., 2020; Arlinghaus et al., 2019). In this context, lack of data can hinder the performance of standard stock assessments, which are an important instrument in the effective and sustainable management of fish stocks (Hilborn et al., 2020; Melnychuk et al., 2017). The application of COMs and ensemble models can be used to deliver insights into stock status when the only fisheries data available are observations of aggregated landings. Here, seven different COMs and three different ensemble models were applied in a case study to assess the status of pike in a German lagoon system. They showed that stock status has been declining in recent years and that current $B$ is around $B / B_{M S Y}$, with the decline being predicted both by individual and ensemble COMs as well as by stakeholders.

This study demonstrates an approach for the data-limited stock assessment of mixed-use fisheries until better data become available and complements other recent studies that have shown how marine stock assessment methods can be used in small-scale inland and other small-scale fisheries in transitional waters, such as coastal lagoons (Fitzgerald et al., 2018; Shephard et al., 2021). The present work also demonstrates that recreational fisheries removals are important to be considered in stock assessments where recreational angling makes up a relevant share of total removals. In this case, neglecting recreational fishing removals lead to an assessment result that indicated a strongly overfished stock due to a long-term decreasing trend in commercial landings. In contrast, by incorporating recreational removals, the total removals time series trend showed long-term stability of removals up until a recent spike and a subsequent decline, resulting in an assessment that estimates a fully exploited stock status.

The results of the present case study indicate that the Rügen pike stock is currently fully exploited, but may experience first signs of growth overfishing $\left(F>F_{\mathrm{MSY}}\right)$. Accordingly, current biomass trends are showing a decline. Commercial and recreational fishing mortality are both relevant factors, and removals from recreational fishing are currently outweighing commercial fisher removals, despite recent catch-and-release rates of pike in Rügen by recreational fishers exceeding 60\% (Arlinghaus et al., 2021; Weltersbach et al., 2021). Additionally, environmental changes unrelated to fishing may also contribute to the present decline. Previous work on recreational use of pike in inland lakes in the USA has revealed ample variation in recreational fishing-induced pike exploitation rates (Pierce et al., 
FIGURE 4 Results of the ensemble model estimates of mean and slope of $B / B_{M S Y}$ over the last five years of data, including their overall mean, overlaid on a truncated time series of individual catch-only model results. The horizontal dotted line indicates $\boldsymbol{B}_{\text {MSY }}$. Results are shown when all removals are considered in the model fitting (a) and when only commercial removals are considered in the model fitting (b)

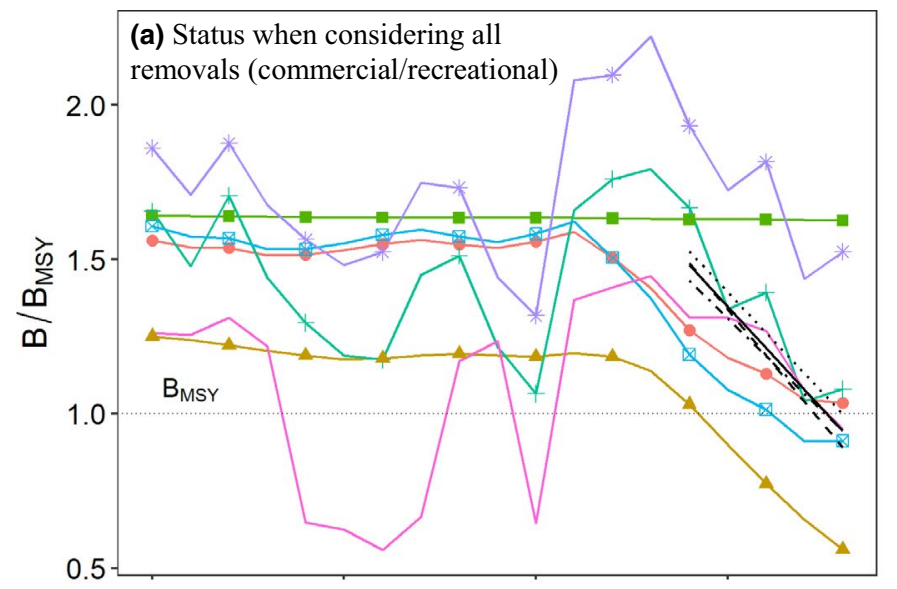

Individual COM
- Catch-MSY
$\approx$ CMSY
- COM-SIR
+ MPRM
$\approx$ OCOM
$*$ SSCOM
- zBRT

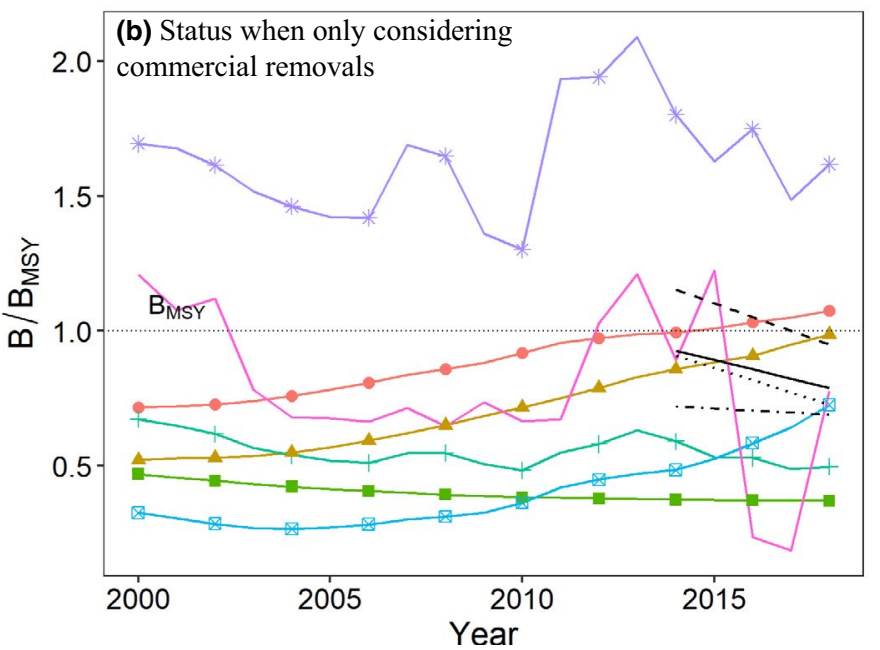

Superensemble model

... Boosted regression

.- Linear model

- Mean

- - Random forest
TABLE 2 Catch-only models and their weight in calculating weighted means of biomass and fishing mortality time series, as well as reference points, for the Rügen pike stock

\begin{tabular}{ll} 
Model & $\begin{array}{l}\text { Normalised } \\
\text { weight }\end{array}$ \\
Catch-MSY & 0.556 \\
CMSY & 0.104 \\
COM-SIR & 0.107 \\
OCOM & 0.232 \\
\hline
\end{tabular}

1995), but the current fishing mortality rate estimated for Rügen pike $(F=0.19 / \mathrm{yr}$ ) is moderate compared with those found for pike stocks in other lakes in the USA (Pierce et al., 1995). However, the performance analysis of the weighting procedure by which estimates of $F$ were derived suggests that relative status estimates (e.g. $F / F_{\text {MSY }}$ ) are less biased than absolute estimates. Thus, uncertainty of the absolute estimates of current status and MSY reference points is high, and focus should go to the relative status estimates of $F / F_{M S Y}$ and $B / B_{M S Y}$. In terms of $F / F_{M S Y}$, specifically for Germany, roughly $20 \%$ of lentic pike stocks have been found to experience fishing mortality rates that are larger than $F_{\text {MSY }}$ (Arlinghaus et al., 2018), and the Rügen pike stock thus compares with intensively fished lake pike stocks.

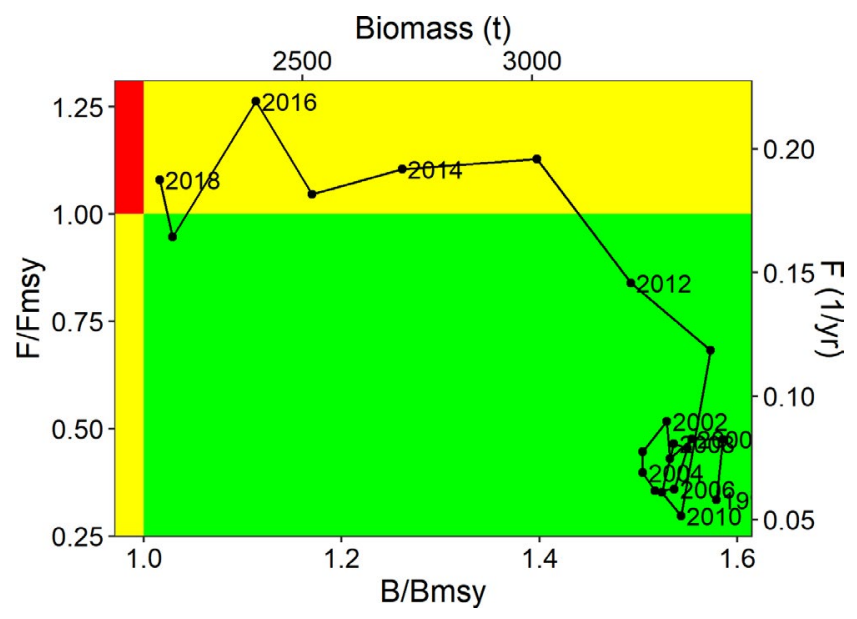

FIGURE 5 Kobe plot showing the weighted means of $B, B / B_{M S Y}$ $F$ and $F / F_{M S Y}$ for the years 1998 to 2018 . The green area indicates healthy stock status, the yellow areas indicate that the stock is either overfished $\left(\boldsymbol{B} / \boldsymbol{B}_{\mathrm{MSY}}<1\right)$ or subject to overfishing $\left(\boldsymbol{F} / \boldsymbol{F}_{\mathrm{MSY}}>1\right)$, and the red area indicates that the stock is both overfished and subject to overfishing

The status of the Rügen pike stock was assessed in the present study using MSY-derived metrics. However, when it comes to mixed-use fisheries, a core question is whether MSY represents the 
optimal measure for defining stock status (Arlinghaus et al., 2019). For commercial fishers, it has often been suggested that maximum economic yield (MEY) rather than MSY would be a more suitable measure for defining stock status, for two main reasons. Firstly, a stock that is fished at a level that returns MEY instead of MSY would be more desirable from most commercial fishers' point of view (Norman-López \& Pascoe, 2011), whilst secondly the stock would also have a higher overall biomass (Grafton et al., 2007). For many recreational fishers, measures of optimal fish status relate more to individual fish size and abundance (i.e. catch rate; Arlinghaus et al., 2014; Beardmore et al., 2015; Birdsong et al., 2021), rather than maximum biomass yield (Johnston et al., 2010), and the benefits of a fish stock to recreational fishers are thus usually maximised at lower fishing mortality rates than those that produce MSY (Ahrens et al., 2020; Hilborn, 2007; Radomski et al., 2001). For instance, size truncation reduces the satisfaction of those recreational fishers that prefer large pike in the catch (Arlinghaus et al., 2014, 2020; Beardmore et al., 2015). Note that keeping fishing mortality rates below MSY can still produce "pretty good yield" (Hilborn, 2010), and thus also please strongly consumptive anglers and commercial fishers in addition to those anglers that value just catch rate or the size of fish in the catch (Ahrens et al., 2020; Gwinn et al., 2015). Current biomass trends of the Rügen pike are negative and around

TABLE 3 Estimates of the 2018 state of the Rügen pike stock, fisheries reference points and population growth parameters, including $95 \%$ confidence limits

\begin{tabular}{llll}
\hline Estimate & Value & $\begin{array}{l}\text { Lower } \\
\text { limit }\end{array}$ & $\begin{array}{l}\text { Upper } \\
\text { limit }\end{array}$ \\
\hline $2018 F\left(\right.$ year $\left.^{-1}\right)$ & 0.19 & 0.093 & 0.50 \\
\hline $2018 B(t)$ & 2229 & 590 & 7334 \\
\hline$M S Y(t)$ & 353 & 207 & 626 \\
\hline$F_{\text {MSY }}\left(\right.$ year $\left.^{-1}\right)$ & 0.17 & 0.055 & 0.37 \\
$B_{\text {MSY }}(t)$ & 2131 & 1053 & 4951 \\
$r\left(\right.$ year $\left.^{-1}\right)$ & 0.35 & 0.11 & 0.75 \\
$k(t)$ & 4262 & 2106 & 9902 \\
\hline
\end{tabular}

Note: Estimates are calculated as a weighted mean of four COMs: Catch-MSY, CMSY, COM-SIR and OCOM.
$B_{M S Y}$, meaning the stock status is size-overfished and thus may be far from optimal from a recreational fishing point of view. In this study, all of the COMs that were applied make use of MSY reference points for defining stock status. Using MSY as a reference by which stock status should be compared is widely accepted in fisheries literature and is perhaps the most common method of doing so. However, it is acknowledged that MSY reference points are not always a suitable measure of stock status, particularly for recreational fishers (Arlinghaus et al., 2019). The use of alternative measures by which stock status, and more generally fishery quality, can be quantified in mixed-use fisheries is therefore encouraged.

Many of the models that were used to derive biomass trends of the Rügen pike stock assume a constant natural environment and stationary population dynamics. However, this has not been the case in the waters around Rügen. Nutrient load greatly increased from the 1950s to the 1980s (Munkes, 2005), after which it has been steadily declining again (LUNG, 2013). Furthermore, submerged macrophyte coverage has greatly deceased in the Greifswalder lagoon and in the Darss-Zingster lagoons due to eutrophication (Kanstinger et al., 2018; Pankow \& Wasmund, 1994). Although submerged macrophyte coverage has remained roughly constant over time in the Westrügen lagoons compared with 1932, it has changed in species composition since then (Blindow et al., 2016). These environmental changes could have affected the productivity of the pike stock, thereby changing the relationship between population abundance and productivity (Vert-Pre et al., 2013), and thus potentially impacting the values of both $B$ and $B_{M S Y}$ over the years independent of fishing pressure (Jensen, 2005; Rose, 2004). In the Darss-Zingster lagoons for instance, increased eutrophication has been thought to be responsible for a decline in pike in favour of pikeperch in the late 1960s (Winkler, 2002). Other changes such as recent warming might have increased pike productivity, but research on this topic from Baltic pike in Sweden has shown that although juvenile growth rate might have benefited from recent warming, adult growth rates have declined (Berggren, 2019). Declines in adult growth rate usually negatively affect population growth rate in pike (Edeline et al., 2010). Furthermore, mean salinity in the region is variable (Möller et al., 2019; Schumann et al., 2006), which can affect hatching rates and recruitment of the stenohaline pike (Jørgensen et al., 2010).

\begin{tabular}{r|ccc|} 
& $(\mathbf{a})$ & Large pike stock change & \\
Others $(\mathrm{n}=23)$ & $62 \%$ & $38 \%$ & $0 \%$ \\
Guide $(\mathrm{n}=13)$ & $77 \%$ & $23 \%$ & $0 \%$ \\
Angler with guide $(\mathrm{n}=180)$ & $77 \%$ & $19 \%$ & $4 \%$ \\
Private angler $(\mathrm{n}=42)$ & $54 \%$ & $37 \%$ & $9 \%$ \\
\hline
\end{tabular}

\begin{tabular}{|c|c|c|c|c|c|}
\hline \multirow[b]{2}{*}{ Others $(n=23)$} & \multicolumn{2}{|l|}{ (b) } & \multicolumn{3}{|c|}{ Pike stock change } \\
\hline & $53 \%$ & & $40 \%$ & & $7 \%$ \\
\hline Guide $(n=13)$ & $85 \%$ & & $8 \%$ & & $8 \%$ \\
\hline Angler with guide $(n=180)$ & $82 \%$ & & $17 \%$ & & $2 \%$ \\
\hline Private angler $(n=42)$ & $54 \%$ & & $38 \%$ & & $8 \%$ \\
\hline & 100 & 50 & $\begin{array}{c}0 \\
\text { Percen }\end{array}$ & 50 & 100 \\
\hline
\end{tabular}

Strong decrease
Similar stock size

Slight increase
Strong increase
FIGURE 6 Stakeholder perceptions $(n=258)$ regarding the recent trends in the number of large pike of the Rügen stock (a) and the total size of the Rügen pike stock (b) 
Generally, unaccounted environmental or habitat-driven changes in stock productivity that happened throughout a time series of landings affect stock assessment outcomes and create relevant uncertainty in assessment results (Brown et al., 2019). However, more complex and data-rich age-structured models often face a similar issue. Variability in somatic growth can be incorporated in Virtual Population Analysis by determining year-specific growth, but is often assumed to be constant in contemporary statistical stock assessment models such as Stock Synthesis (Stawitz et al., 2019; Whitten et al., 2013). Furthermore, adult natural mortality is almost always assumed to be constant over time regardless of model specification (Jiao et al., 2012; Johnson et al., 2015).

Multiple different COMs have been developed over the years to estimate stock status under data-limited conditions. To be able to run with limited data, these COMs make a variety of simplifying assumptions, increasing the chances for bias and uncertainty of their estimate (Anderson et al., 2017; Bouch et al., 2021; Free et al., 2020; Rosenberg et al., 2014). Therefore, using only a single COM for assessing stock status increases the risk of producing a flawed or biased status estimate. This is supported by the results of the present case study, which showed a large spread in individual COM predictions, as well as by the results of the model performance analysis. Thus, using only a single COM to estimate stock status should be avoided. Instead, the use of multiple different models, with the final estimated value either being the mean of all models or the product of some weighting procedure, is expected to increase the robustness of the result (Bates \& Granger, 1969).

Although a simple model averaging approach could improve estimates of stock status, it will not take into account that some models perform better or worse under certain conditions. A statistical ensemble model, on the other hand, allows for exploiting the covariance between individual COM predictions (Anderson et al., 2017), allowing for a better accounting of individual model biases. In the present case study, three different types of such statistical ensemble models were applied, and it was found that their estimates of recent biomass status were relatively similar, increasing the confidence in their results. The results of the model performance analysis further support confidence in the ensemble model results, showing that they have a higher accuracy than individual COMs and are relatively unbiased, both for estimating mean and slope of $B / B_{M S Y}$ over the last 5 years of data. However, ensemble models of COMs generally produce a negatively biased estimate of stock status for lightly exploited stocks (Free et al., 2020). Thus, it is possible that the pike stock in the present case study is actually in a better shape than suggested by the ensemble models, although the recent spike in total removals would not be typical for a lightly exploited stock, and the performance analysis of the weighting procedure showed no directional bias for $B / B_{M S Y}$ in recent years.

Furthermore, the predominant reliance of COMs on landings time series means that it is important that these data are reliable and of high quality. For many mixed-use fisheries this is rarely the case, with data on recreational removals often missing or incomplete (Arlinghaus et al., 2019). Commercial landings statistics may also suffer from illegal and unreported catch (Agnew et al., 2009). In the present case study, a time series of recreational removals was reconstructed using two local scientific studies as anchor points, and using various other forms of time series data to interpolate between and extrapolate from these points. Such reconstructions should be paired with rigorous sensitivity analyses. Even though the sensitivity of the model results was tested to various alternative reconstruction approaches and limited impact was found, the possibility cannot be excluded that the reconstruction of recreational removals contained uncertainty. Nevertheless, the results showed that it is advisable to reconstruct recreational fishing removals, even when uncertain, instead of solely relying on commercial landings data. Thus, in the absence of sufficient data to perform more sophisticated assessments that incorporate age data, COMs may provide approximations of stock status, as long as uncertainties are recognised and explored. This study tested several sensitivities and found the results to be largely robust and additionally mirrored by stakeholder perceptions.

There is still an active debate among fisheries scientists on whether catch-only methods should be used at all for assessing fish stock status. Some argue that catch data represent the only data available for many data-limited fish stocks and that using catch-only methods provides the only option of getting an indication of the status of those stocks, even if they are less precise than data-rich stock assessments (Froese et al., 2012; Pauly et al., 2013). Others argue that it is better not to use catch-only methods when they may be wrong and that instead the focus should be on collecting and including additional data (Branch et al., 2011; FAO, 2019). Some of this debate may be resolved by accounting explicitly for the higher levels of uncertainty of data-limited methods through precautionary management measures or buffers (Dowling et al., 2019). For instance, Walsh et al. (2018) found that using ensembles of catch-only models to inform fisheries management could reduce the risk of overfishing, but only when combined with a precautionary harvest control rule, which in turn might result in poor yields. Thus, the usage of COMs and ensembles in the management of mixed-use fisheries should be combined with a precautionary approach, and whenever possible additional data should be collected to allow for more datarich assessments. For instance, this study added survey data from stakeholders to increase the confidence in the assessment outcomes. Although stakeholder perspectives present their own biases (O'Donnell et al., 2010), the alignment of stakeholder perceptions and COM predictions support the conclusion that pike biomass has declined in recent years.

In conclusion, the present study has used a combination of individual and ensembled COMs and stakeholder surveys to assess the status of a data-poor coastal pike stock that is exploited by both commercial and recreational fishers. This required the reconstruction of the recreational removals time series from related data, and sensitivity analyses were performed to test the assumptions made in this reconstruction. It is concluded that the pike stock is fully exploited, currently declining, and may be experiencing growth overfishing and/or is affected by a recent fishery-independent environmental 
change that reduces productivity and resiliency to harvest. Even if environmental factors are involved, the currently declining biomass trends suggest that reductions in fishing mortality may be advisable, which would apply to both fishers and anglers. This study has shown the benefits of using multiple different models and including stakeholder surveys when assessing stock status through data-limited methods and has also demonstrated the importance of including recreational removals when assessing the status of a stock that is co-exploited by commercial and recreational fisheries.

\section{ACKNOWLEDGEMENTS}

Funding was received through the European Maritime Fisheries Fund (EMFF) of the EU and the State of Mecklenburg-Vorpommern (Germany) (grant B 730117000069, MV-I.18-LM-004) within the Boddenhecht project. We thank C. Free, O. Jensen, D. Ovando and R. Ahrens for discussion and furthermore thank $C$. Free for the sharing of model code and a detailed review of the manuscript draft. Open Access funding enabled and organized by Projekt DEAL.

[Correction added on 18 September 2021, after first online publication: Projekt Deal funding statement has been added.]

\section{CONFLICT OF INTEREST}

There is no conflict of interest.

\section{DATA AVAILABILITY STATEMENT}

The data that support the findings of this study are available from the corresponding author upon reasonable request.

\section{ORCID}

Rob van Gemert (D) https://orcid.org/0000-0001-9395-4740

Robert Arlinghaus (D) https://orcid.org/0000-0003-2861-527X

\section{REFERENCES}

Agnew, D.J., Pearce, J., Pramod, G., Peatman, T., Watson, R., Beddington, J.R. et al. (2009) Estimating the worldwide extent of illegal fishing. PLoS One, 4(2), e4570.

Ahrens, R.N.M., Allen, M.S., Walters, C. \& Arlinghaus, R. (2020) Saving large fish through harvest slots outperforms the classical minimumlength limit when the aim is to achieve multiple harvest and catchrelated fisheries objectives. Fish and Fisheries, 21(3), 483-510.

Aminpour, P., Gray, S.A., Jetter, A.J., Introne, J.E., Singer, A. \& Arlinghaus, R. (2020) Wisdom of stakeholder crowds in complex socialecological systems. Nature Sustainability, 3(3), 191-199.

Anderson, S.C. (2021) fishensembles: Create Fisheries Superensemble Models. R package version 0.0.2. Available from: https://github. com/datalimited/fishensembles. Accessed June 14, 2021.

Anderson, S.C., Afflerbach, J., Cooper, A.B., Dickey-Collas, M., Jensen, O.P., Kleisner, K.M. et al. (2016) Datalimited: stock assessment methods for data-limited fisheries. Available from: https://github.com/ datalimited/datalimited. Accessed June 14, 2021.

Anderson, S.C., Cooper, A.B., Jensen, O.P., Minto, C., Thorson, J.T., Walsh, J.C. et al. (2017) Improving estimates of population status and trend with superensemble models. Fish and Fisheries, 18(4), 732-741.

Andrew, N.L., Béné, C., Hall, S.J., Allison, E.H., Heck, S. \& Ratner, B.D. (2007) Diagnosis and management of small-scale fisheries in developing countries. Fish and Fisheries, 8(3), 227-240.
Arlinghaus, R., Abbott, J.K., Fenichel, E.P., Carpenter, S.R., Hunt, L.M., Alós, J. et al. (2019) Opinion: governing the recreational dimension of global fisheries. Proceedings of the National Academy of Sciences, 116(12), 5209-5213.

Arlinghaus, R., Alós, J., Beardmore, B., Díaz, Á.M., Hühn, D., Johnston, F. et al. (2018) Recreational piking-sustainably managing pike in recreational fisheries. In: Skov, C. \& Nilsson, P.A. (Eds.) Biology and ecology of pike. Baco Raton, FL: CRC Press, pp. 288-336.

Arlinghaus, R., Beardmore, B., Riepe, C., Meyerhoff, J. \& Pagel, T. (2014) Species-specific preferences of German recreational anglers for freshwater fishing experiences, with emphasis on the intrinsic utilities of fish stocking and wild fishes. Journal of Fish Biology, 85(6), 1843-1867.

Arlinghaus, R., Beardmore, B., Riepe, C. \& Pagel, T. (2020) Speciesspecific preference heterogeneity in German freshwater anglers, with implications for management. Journal of Outdoor Recreation and Tourism, 32, 100216.

Arlinghaus, R., Lucas, J., Weltersbach, M.S., Kömle, D., Winkler, H.M., Riepe, C. et al. (2021) Niche overlap among anglers, fishers and cormorants and their removals of fish biomass: a case from brackish lagoon ecosystems in the southern Baltic Sea. Fisheries Research, 238, 105894.

Aswani, S. \& Hamilton, R.J. (2004) Integrating indigenous ecological knowledge and customary sea tenure with marine and social science for conservation of bumphead parrotfish (Bolbometopon muricatum) in the Roviana Lagoon, Solomon Islands. Environmental conservation, 31(1), 69-83.

Bates, J.M. \& Granger, C.W. (1969) The combination of forecasts. Journal of the Operational Research Society, 20(4), 451-468.

Beardmore, B., Hunt, L.M., Haider, W., Dorow, M. \& Arlinghaus, R. (2015) Effectively managing angler satisfaction in recreational fisheries requires understanding the fish species and the anglers. Canadian Journal of Fisheries and Aquatic Sciences, 72(4), 500-513.

Berggren, T. (2019) Increased body growth rates of northern pike (Esox lucius) in the Baltic Sea. Master's Thesis, Swedish University of Agricultural Sciences, Department of Aquatic Resources. Öregrund.

Berkes, F. (1985) Fishermen and 'The Tragedy of the Commons'. Environmental Conservation, 12(3), 199-206.

Berkes, F., Colding, J. \& Folke, C. (2000) Rediscovery of traditional ecological knowledge as adaptive management. Ecological applications, 10(5), 1251-1262.

Birdsong, M., Hunt, L.M. \& Arlinghaus, R. (2021) Recreational angler satisfaction: What drives it? Fish and Fisheries, 22(4), 682-706.

Blindow, I., Dahlke, S., Dewart, A., Flügge, S., Hendreschke, M., Kerkow, A. et al. (2016) Long-term and interannual changes of submerged macrophytes and their associated diaspore reservoir in a shallow southern Baltic Sea bay: influence of eutrophication and climate. Hydrobiologia, 778(1), 121-136.

Bouch, P., Minto, C. \& Reid, D.G. (2021) Comparative performance of data-poor CMSY and data-moderate SPiCT stock assessment methods when applied to data-rich, real-world stocks. ICES Journal of Marine Science, 78(1), 264-276.

Branch, T.A., Jensen, O.P., Ricard, D., Ye, Y. \& Hilborn, R. (2011) Contrasting global trends in marine fishery status obtained from catches and from stock assessments. Conservation Biology, 25(4), 777-786.

Brown, C.J., Broadley, A., Adame, M.F., Branch, T.A., Turschwell, M.P. \& Connolly, R.M. (2019) The assessment of fishery status depends on fish habitats. Fish and Fisheries, 20(1), 1-14.

Carruthers, T.R., Walters, C.J. \& McAllister, M.K. (2012) Evaluating methods that classify fisheries stock status using only fisheries catch data. Fisheries Research, 119, 66-79.

Cooke, S.J. \& Cowx, I.G. (2004) The role of recreational fishing in global fish crises. BioScience, 54(9), 857-859.

Costello, C., Ovando, D., Hilborn, R., Gaines, S.D., Deschenes, O. \& Lester, S.E. (2012) Status and solutions for the world's unassessed fisheries. Science, 338(6106), 517-520. 
Daan, N., Gislason, H., Pope, J.G. \& Rice, J.C. (2011) Apocalypse in world fisheries? The reports of their death are greatly exaggerated. ICES Journal of Marine Science, 68(7), 1375-1378.

Daw, T.M., Robinson, J.A.N. \& Graham, N.A. (2011) Perceptions of trends in Seychelles artisanal trap fisheries: comparing catch monitoring, underwater visual census and fishers' knowledge. Environmental Conservation, 38(1), 75-88.

Döring, R., Berkenhagen, J., Hentsch, S. \& Kraus, G. (2020) Small-scale fisheries in germany: a disappearing profession? Small-scale fisheries in europe: status, resilience and governance. Cham: Springer, pp. 483-502.

Dorow, M. \& Arlinghaus, R. (2011) A telephone-diary-mail approach to survey recreational fisheries on large geographic scales, with a note on annual landings estimates by anglers in northern Germany. American Fisheries Society Symposium, 75(1), 319-344.

Dowling, N.A., Smith, A.D.M., Smith, D.C., Parma, A.M., Dichmont, C.M., Sainsbury, K. et al. (2019) Generic solutions for data-limited fishery assessments are not so simple. Fish and Fisheries, 20(1), 174-188.

Edeline, E., Haugen, T.O., Weltzien, F.-A., Claessen, D., Winfield, I.J., Stenseth, N.C. et al. (2010) Body downsizing caused by non-consumptive social stress severely depresses population growth rate. Proceedings of the Royal Society B: Biological Sciences, 277(1683), 843-851.

FAO. (2019) Report of the expert consultation workshop on the development of methodologies for the global assessment of fish stock status, 4-6 February 2019. Rome: FAO Fisheries and Aquaculture Report, p. 47.

Fitzgerald, C.J., Delanty, K. \& Shephard, S. (2018) Inland fish stock assessment: applying data-poor methods from marine systems. Fisheries Management and Ecology, 25(4), 240-252.

Free, C.M. (2018) datalimited2: More stock assessment methods for datalimited fisheries. R package version 0.1.0. Available from: https:// github.com/cfree14/datalimited2. Accessed June 14, 2021.

Free, C.M., Jensen, O.P., Anderson, S.C., Gutierrez, N.L., Kleisner, K.M., Longo, C. et al. (2020) Blood from a stone: Performance of catchonly methods in estimating stock biomass status. Fisheries Research, 223, 105452.

Froese, R., Demirel, N., Coro, G., Kleisner, K.M. \& Winker, H. (2017) Estimating fisheries reference points from catch and resilience. Fish and Fisheries, 18(3), 506-526.

Froese, R. \& Kesner-Reyes, K. (2002) Impact of fishing on the abundance of marine species. Copenhagen: ICES.

Froese, R., Zeller, D., Kleisner, K. \& Pauly, D. (2012) What catch data can tell us about the status of global fisheries. Marine Biology, 159(6), 1283-1292.

Graaf, G.D., Bartley, D., Jorgensen, J. \& Marmulla, G. (2015) The scale of inland fisheries, can we do better? Alternative approaches for assessment. Fisheries Management and Ecology, 22(1), 64-70.

Grafton, R.Q., Kompas, T. \& Hilborn, R.W. (2007) Economics of overexploitation revisited. Science, 318(5856), 1601.

Grainger, R.J. \& Garcia, S.M. (1996) Chronicles of marine fishery landings (1950-1994): trend analysis and fisheries potential. Rome: FAO.

Greenwell, B., Boehmke, B., Cunningham, J. \& Developers, G.B.M. (2019) gbm: Generalized Boosted Regression Models. Available from: https:// CRAN.R-project.org/package $=$ gbm. Accessed June 14, 2021

Gwinn, D.C., Allen, M.S., Johnston, F.D., Brown, P., Todd, C.R. \& Arlinghaus, R. (2015) Rethinking length-based fisheries regulations: the value of protecting old and large fish with harvest slots. Fish and Fisheries, 16(2), 259-281.

Hart, P.J. \& Reynolds, J.D. (2002) Handbook of fish biology and fisheries. Volume 2, Fisheries. Oxford: Oxford, Blackwell Publishing.

Hilborn, R. (2007) Defining success in fisheries and conflicts in objectives. Marine Policy, 31(2), 153-158.

Hilborn, R. (2010) Pretty good yield and exploited fishes. Marine Policy, 34(1), 193-196.

Hilborn, R., Amoroso, R.O., Anderson, C.M., Baum, J.K., Branch, T.A., Costello, C. et al. (2020) Effective fisheries management instrumental in improving fish stock status. Proceedings of the National Academy of Sciences, 117(4), 2218-2224.

Hilborn, R. \& Walters, C.J. (1992) Quantitative fisheries stock assessment: choice, dynamics and uncertainty. London: Chapman \& Hall.

Hühn, D. \& Arlinghaus, R. (2011) Determinants of hooking mortality in freshwater. American Fisheries Society Symposium, 75, 141-170.

Jensen, A.L. (2005) Harvest in a fluctuating environment and conservative harvest for the Fox surplus production model. Ecological Modelling, 182(1), 1-9.

Jiao, Y., Smith, E.P., O'Reilly, R. \& Orth, D.J. (2012) Modelling nonstationary natural mortality in catch-at-age models. ICES Journal of Marine Science, 69(1), 105-118.

Johannes, R.E. (1998) The case for data-less marine resource management: examples from tropical nearshore finfisheries. Trends in Ecology \& Evolution, 13(6), 243-246.

Johnson, K.F., Monnahan, C.C., McGilliard, C.R., Vert-pre, K.A., Anderson, S.C., Cunningham, C.J. et al. (2015) Time-varying natural mortality in fisheries stock assessment models: identifying a default approach. ICES Journal of Marine Science, 72(1), 137-150.

Johnston, F.D., Arlinghaus, R. \& Dieckmann, U. (2010) Diversity and complexity of angler behaviour drive socially optimal input and output regulations in a bioeconomic recreational-fisheries model. Canadian Journal of Fisheries and Aquatic Sciences, 67(9), 1507-1531.

Jørgensen, A.T., Hansen, B.W., Vismann, B., Jacobsen, L., Skov, C., Berg, S. et al. (2010) High salinity tolerance in eggs and fry of a brackish Esox lucius population. Fisheries Management and Ecology, 17(6), 554-560.

Kanstinger, P., Beher, J., Grenzdörffer, G., Hammer, C., Huebert, K.B., Stepputis, D. et al. (2018) What is left? Macrophyte meadows and Atlantic herring (Clupea harengus) spawning sites in the Greifswalder Bodden, Baltic Sea. Estuarine, Coastal and Shelf Science, 201, 72-81.

Kuhn, M. (2020) caret: Classification and Regression Training. R package version 6.0-86. Available from: https://CRAN.R-project.org/packa ge $=$ caret. Accessed June 14, 2021.

Liaw, A. \& Wiener, M. (2002) Classification and regression by randomForest. $R$ News, 2(3), 18-22.

Lucas, J. (2018) Recreational fishing in the Bodden waters of the Southern Baltic Sea - Touristic potential and implications for management. Master's Thesis, Humboldt-Universität zu Berlin / Leibniz-Institut für Gewässerökologie und Binnenfischerei (IGB) in Berlin / ThünenInstitut: Ostseefischerei. Berlin.

LUNG. (2013) Zur Entwicklung und zum Stand der Nährstoffbelastung der Küstengewässer Mecklenburg-Vorpommerns. Berichte zur Gewässergüte, herausgegeben vom Landesamt für Umwelt, Naturschutz und Geologie Mecklenburg-Vorpommern (LUNG), Güstrow, pp. 22

Mangin, T., Costello, C., Anderson, J., Arnason, R., Elliott, M., Gaines, S.D. et al. (2018) Are fishery management upgrades worth the cost? PLoS One, 13(9), e0204258.

Mardle, S., Pascoe, S. \& Herrero, I. (2004) Management objective importance in fisheries: an evaluation using the analytic hierarchy process (AHP). Environmental Management, 33(1), 1-11.

Martell, S. \& Froese, R. (2013) A simple method for estimating MSY from catch and resilience. Fish and Fisheries, 14(4), 504-514.

Melnychuk, M.C., Peterson, E., Elliott, M. \& Hilborn, R. (2017) Fisheries management impacts on target species status. Proceedings of the National Academy of Sciences, 11(1), 178-183.

Möller, S., Winkler, H.M., Klügel, A. \& Richter, S. (2019) Using otolith microchemical analysis to investigate the importance of brackish bays for pike (Esox lucius Linnaeus, 1758) reproduction in the southern Baltic Sea. Ecology of Freshwater Fish, 28(4), 602-610.

Munkes, B. (2005) Eutrophication, phase shift, the delay and the potential return in the Greifswalder Bodden, Baltic Sea. Aquatic Sciences, 67(3), 372-381.

Neis, B., Schneider, D.C., Felt, L., Haedrich, R.L., Fischer, J. \& Hutchings, J.A. (1999) Fisheries assessment: what can be learned from 
interviewing resource users? Canadian Journal of Fisheries and Aquatic Sciences, 56(10), 1949-1963.

Newman, D., Berkson, J. \& Suatoni, L. (2015) Current methods for setting catch limits for data-limited fish stocks in the United States. Fisheries Research, 164, 86-93.

Norman-López, A. \& Pascoe, S. (2011) Net economic effects of achieving maximum economic yield in fisheries. Marine Policy, 35(4), 489-495.

O'Donnell, K.P., Pajaro, M.G. \& Vincent, A.C.J. (2010) How does the accuracy of fisher knowledge affect seahorse conservation status? Animal Conservation, 13(6), 526-533.

Pankow, H. \& Wasmund, N. (1994) Produktionsbiologie und soziologie des makro-und mikrophytobenthos der Darß-zingster boddenkette. Rostocker Meeresbiologische Beiträge, 2, 61-68.

Pascoe, S., Proctor, W., Wilcox, C., Innes, J., Rochester, W. \& Dowling, N. (2009) Stakeholder objective preferences in Australian Commonwealth managed fisheries. Marine Policy, 33(5), 750-758.

Pauly, D. (2007) The Sea Around Us Project: documenting and communicating global fisheries impacts on marine ecosystems. AMBIO: A Journal of the Human Environment, 36(4), 290-295.

Pauly, D., Hilborn, R. \& Branch, T.A. (2013) Fisheries: Does catch reflect abundance? Nature, 494(7437), 303-306.

Pierce, R.B., Tomcko, C.M. \& Schupp, D.H. (1995) Exploitation of northern pike in seven small north-central Minnesota lakes. North American Journal of Fisheries Management, 15(3), 601-609.

Placke, M., Meier, H.E., Gräwe, U., Neumann, T., Frauen, C. \& Liu, Y. (2018) Long-term mean circulation of the Baltic Sea as represented by various ocean circulation models. Frontiers in Marine Science, 5, 287.

Post, J.R., Sullivan, M., Cox, S., Lester, N.P., Walters, C.J., Parkinson, E.A. et al. (2002) Canada's recreational fisheries: the invisible collapse? Fisheries, 27(1), 6-17.

Prince, J. \& Hordyk, A. (2019) What to do when you have almost nothing: A simple quantitative prescription for managing extremely datapoor fisheries. Fish and Fisheries, 20(2), 224-238.

R Core Team. (2019) R: A language and environment for statistical computing. Vienna, Austria: R foundation for Statistical Computing. Available from: https://www.R-project.org/. Accessed June 14, 2021.

Radomski, P.J., Grant, G.C., Jacobson, P.C. \& Cook, M.F. (2001) Visions for recreational fishing regulations. Fisheries, 26(5), 7-18.

Rose, G.A. (2004) Reconciling overfishing and climate change with stock dynamics of Atlantic cod (Gadus morhua) over 500 years. Canadian Journal of Fisheries and Aquatic Sciences, 61(9), 1553-1557.

Rosenberg, A.A., Fogarty, M.J., Cooper, A.B., Dickey-Collas, M., Fulton, E.A., Gutiérrez, N.L. et al. (2014) Developing new approaches to global stock status assessment and fishery production potential of the seas. Rome: FAO, p. 175.

Schiewer, U. (2008) Ecology of Baltic coastal waters. Berlin: Springer.

Schubert, H. \& Telesh, I. (2017) Estuaries and coastal lagoons. In: Snoeijs-Leijonmalm, P., Schubert, H. \& Radziejewska, T. (Eds.), Biological oceanography of the Baltic Sea. Dordrecht: Springer, pp. 483-509.

Schumann, R., Baudler, H., Glass, Ä., Dümcke, K. \& Karsten, U. (2006) Long-term observations on salinity dynamics in a tideless shallow coastal lagoon of the Southern Baltic Sea coast and their biological relevance. Journal of Marine Systems, 60(3-4), 330-344.

Shephard, S., Valbo-Jorgensen, J., Abadía, J., Baigún, C., Doria, C.R.C., Fabré, N.N. et al. (2021) From Amazon catfish to Mekong money fish: size-based assessment of data-limited commercial inland fisheries. American Fisheries Society, 46(4), 170-187.

Stawitz, C.C., Haltuch, M.A. \& Johnson, K.F. (2019) How does growth misspecification affect management advice derived from an integrated fisheries stock assessment model? Fisheries Research, 213, 12-21.

Thorson, J.T., Minto, C., Minte-Vera, C.V., Kleisner, K.M. \& Longo, C. (2013) A new role for effort dynamics in the theory of harvested populations and data-poor stock assessment. Canadian Journal of Fisheries and Aquatic Sciences, 7(12), 1829-1844.
Vasconcellos, M. \& Cochrane, K. (2005) Overview of world status of data-limited fisheries: inferences from landings statistics. In: Kruse, G.H., Gallucci, V.F., Hay, D.E., Perry, R.I., Peterman, R.M., Shirley, T.C., Spencer, P.D., Wilson, B. \& Woodby, D. (Eds.), Fisheries assessment and management in data-limited situations. Alaska Sea Grant: University of Alaska Fairbanks, pp. 1-20.

VDFF. (1998) 50 Jahre Fischerei in Deutschland 1948-1998, Heft 12, Jubiläumsschrift zum 50 jährigen Bestehen. Ulrich-Druck: Fürth.

Vert-Pre, K.A., Amoroso, R.O., Jensen, O.P. \& Hilborn, R. (2013) Frequency and intensity of productivity regime shifts in marine fish stocks. Proceedings of the National Academy of Sciences, 110(5), 1779-1784.

Vogt, A. (2020) Understanding stakeholder conflicts in coastal fisheries: evidence from the brackish lagoons around Rügen, Germany. Master Thesis, Humboldt-Universität zu Berlin, Leibniz-Institut für Gewässerökologie und Binnenfischerei (IGB), Berlin.

Walsh, J.C., Minto, C., Jardim, E., Anderson, S.C., Jensen, O.P., Afflerbach, J. et al. (2018) Trade-offs for data-limited fisheries when using harvest strategies based on catch-only models. Fish and Fisheries, 19(6), 1130-1146.

Weltersbach, M.S., Riepe, C., Lewin, W.C. \& Strehlow, H.V. (2021) Ökologische, soziale und ökonomische Dimensionen des Meeresangelns in Deutschland. Braunschweig: Johann Heinrich von ThünenInstitut, Thünen Rep 83, pp. 254.

Whitten, A.R., Klaer, N.L., Tuck, G.N. \& Day, R.W. (2013) Accounting for cohort-specific variable growth in fisheries stock assessments: a case study from south-eastern Australia. Fisheries Research, 142, 27-36.

Winkler, H.M. (1989) Fische und fangerträge im greifswalder bodden. Meer und Museum, 5, 51-58.

Winkler, H.M. (1991) Changes of structure and stock in exploited fish communities in estuaries of the Southern Baltic Coast (Mecklenburg-Vorpommern, Germany). Internationale Revue der gesamten Hydrobiologie und Hydrographie, 76(3), 413-422.

Winkler, H.M. (2002) Effects of eutrophication on fish stocks in Baltic lagoons. In: Schernewski, G. \& Schiewer, U. (Eds.) Baltic coastal ecosystems. Berlin: Springer, pp. 65-74.

Winkler, H.M. \& Debus, L. (2006) Auffällige Bestandsveränderungen bei wichtigen Fischarten der Darß-Zingster Boddenkette und mögliche Ursachen. Rostocker Meeresbiologische Beiträge, 16, 61-70.

Zeller, D., Booth, S., Craig, P. \& Pauly, D. (2006) Reconstruction of coral reef fisheries catches in American Samoa, 1950-2002. Coral Reefs, 25(1), 144-152.

Zhou, S., Punt, A.E., Smith, A.D.M., Ye, Y., Haddon, M., Dichmont, C.M. et al. (2018) An optimized catch-only assessment method for data poor fisheries. ICES Journal of Marine Science, 75(3), 964-976.

Zhou, S., Punt, A.E., Ye, Y., Ellis, N., Dichmont, C.M., Haddon, M. et al. (2017) Estimating stock depletion level from patterns of catch history. Fish and Fisheries, 18(4), 742-751.

\section{SUPPORTING INFORMATION}

Additional supporting information may be found in the online version of the article at the publisher's website.

How to cite this article: van Gemert, R., Koemle, D., Winkler, H. \& Arlinghaus, R. (2022) Data-poor stock assessment of fish stocks co-exploited by commercial and recreational fisheries: Applications to pike Esox lucius in the western Baltic Sea. Fisheries Management and Ecology, 29, 16-28. https://doi. org/10.1111/fme.12514 